\title{
On earth, peace and good will and a fair go for all
}

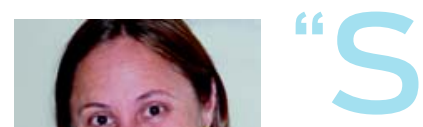

ocial injustice kills", wrote Professor Sir Michael Marmot and colleagues (Lancet 2012; 380: 1011-

1029). They were presenting the recommendations of the European Review of Social Determinants of Health and the Health Divide, which addressed inequities across the region - and, essentially, were making the moral case for action. Social injustice leads to unnecessary, expensive and undesirable outcomes, they said, and no society can afford inaction. The European Review's key message is a simple one: "do something, do more, do better". In this, the MJA's Christmas issue and our last for 2012, contributors from Australia's health care community indicate some of what has been, can be, and needs to be done at home.

Australians enjoy publicly funded universal health care via Medicare but there are well known pockets of inequity. A number of measures introduced in primary care have sought to channel services to those who most need them. The Chronic Disease Dental Scheme was one such measure, which allowed eligible patients up to $\$ 4250$ Medicare-funded dental services over 2 consecutive years.

On 1 December 2012 the scheme ceased, amid claims that it was poorly targeted, easily rorted and too expensive. Contrary to these concerns, Knott and colleagues (page 625)

Ruth Armstrong Senior Deputy Editor

mja@mja.com.au

doi: 10.5694/mjal2.c1210 have found, using nationwide data from the Australian Hypertension and Absolute Risk Study (AusHEART), that the scheme - at least in the period after its introduction - was, in fact, accessed by the low-income households who most needed it. A new scheme will replace the old one: we join Harris (page 598) in the wish for something even more progressive.

Obesity and its complications are somewhat subject to a socioeconomic gradient (where health is progressively better the higher the socioeconomic position of people and communities). Bariatric surgery procedures have been listed on the Medicare Benefits Schedule (MBS) for the management of severe obesity since 1992. Using statewide (New South Wales) data from the prospective cohort study 45 and Up, Korda and colleagues (page 631) found that these procedures are mostly accessed by those who can afford private health insurance and associated out-of-pocket costs. Inequalities could decline if indications for bariatric surgery became less discretionary over time - for example, if they were extended to include management of type 2 diabetes.

The European Review said that the highest priority is for countries to ensure a good start to life for every child. In the Northern Territory in Australia, the Little children are sacred report of 2007, which stated that "sexual abuse of Aboriginal children is common, widespread, and grossly

underreported", sparked a controversial federal government response and led to an ongoing suite of initiatives including new reporting obligations for child maltreatment. Guthridge and colleagues (page 637) have examined the subsequent rapid increase in both notifications of suspected maltreatment and substantiated cases. While it is not known how closely these reports reflect actual incidence, there is a clear need to better address the wider, social determinants of maltreatment.

In many developing countries, the HIV epidemic is exacerbated by laws that further disadvantage stigmatised groups, says the Honourable Michael Kirby (page 607). He highlights an opportunity for Australia to have a positive influence on international law through our newly obtained place on the United Nations Security Council.

Back home, Newman reminds us (page 596) that the asylum seeker issue has become one of the most contested social issues of the past half century in a nation built on immigration. It is to be hoped that, wherever individual doctors stand in the current debate, we can see our way clear as a profession to support initiatives that ensure fair and just access to healthful living conditions and health care for those who seek refuge on our shores.

The moral case for action on health inequality and the socioeconomic gradient is, of course, a global and longstanding one, asserted in the World Health Organization's constitution (1948):

The enjoyment of the highest attainable standard of health is one of the fundamental rights of every human being without distinction of race, religion, political belief, economic or social condition.

This is our wish, this Christmas and every Christmas. We hope it comes true. We hope your wishes come true too.

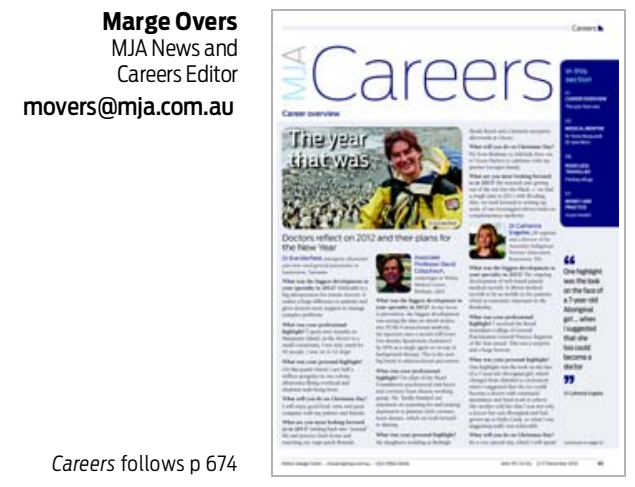

\section{Reflections and rewards}

One of the highlights of 2012 for Dr Catherine Engelke was the look on the face of a young Aboriginal girl who realised that she too could become a doctor. Dr Engelke, a director of the Australian Indigenous Doctors' Association, is one of seven doctors who reflect on 2012 and their hopes for the New Year in this issue of MJA Careers (page C1). In Medical Mentor (page C5), we meet Dr Tonia Marquardt, who returned to remote practice in Australia after a decade with Médecins Sans Frontières, and her mentor and friend, Dr Jane Barry. Road Less Travelled (page C6) profiles Dr Mitchell Smith, who has spent more than two decades working in refugee health. Finally, Money and Practice (page C8) looks at endof-year rewards and celebrations for practice staff, including a Melbourne general practice that knows how to party. 